\title{
Prognostic significance of Ki-67 index value at the primary breast tumor in recurrent breast cancer
}

\author{
REIKI NISHIMURA $^{1}$, TOMOFUMI OSAKO ${ }^{1}$, YASUYUKI NISHIYAMA ${ }^{1}$, RUMIKO TASHIMA $^{2}$, \\ MASAHIRO NAKANO ${ }^{1}$, MAMIKO FUJISUE ${ }^{1}$, YASUO TOYOZUMI ${ }^{3}$ and NOBUYUKI ARIMA ${ }^{3}$ \\ Departments of ${ }^{1}$ Breast and Endocrine Surgery, ${ }^{2}$ Surgery and ${ }^{3}$ Pathology, \\ Kumamoto City Hospital, Kumamoto 862-8505, Japan
}

Received June 2, 2014; Accepted July 17, 2014

DOI: $10.3892 / \operatorname{mco} .2014 .400$

\begin{abstract}
The Ki-67 index value is a prognostic factor in primary breast cancer and is a proliferation marker that also distinguishes between luminal type $\mathrm{A}$ and type $\mathrm{B}$ breast cancer. Moreover, a change in $\mathrm{Ki}-67$ index values due to treatment and recurrence is considered to be important in treating breast cancer. In this study, we investigated whether the baseline $\mathrm{Ki}-67$ value in the primary tumor is useful as a prognostic factor following disease recurrence. Immunohistochemical analysis of the Ki-67 index was performed on 4,701 patients with primary breast cancer from 1987 until March, 2013. Among these patients, there were 666 consecutive cases exhibiting recurrence after primary surgery. The fraction of proliferating cells was based on a count of at least 500 tumor cells in the area including the hot spot. The Ki-67 values were divided into 3 groups, namely $<20, \geq 20$ and $\geq 50 \%$. The investigated items included estrogen receptor (ER), progesterone receptor $(\mathrm{PgR})$, human epidermal growth factor receptor 2 (HER2), tumor size, nodal status for the primary tumor, recurrence site (soft tissue, bone and viscera) and disease-free interval (DFI). The Cox's proportional hazard model was used to perform univariate and multivariate analyses of the factors associated with overall survival (OS) following recurrence. The median follow-up period was 65.9 months in the surviving group. The median Ki-67 value at baseline was $20 \%$ in all the cases and $27 \%$ in the recurrent cases. The Ki-67 values were low $(24 \%)$ in patients with bone metastasis and significantly higher in patients with liver or brain metastasis (38 and 55\%, respectively). Moreover, DFI was found to be inversely correlated with the Ki-67 values. Univariate analysis was performed to identify the prognostic factors for OS after recurrence. The significant factors included tumor size, lymph node status, ER, PgR, DFI, recurrence site and Ki-67 index value. Among these factors, a multivariate analysis identified
\end{abstract}

Correspondence to: Dr Reiki Nishimura, Department of Breast and Endocrine Surgery, Kumamoto City Hospital, 1-1-60 Kotoh, Higashi-ku, Kumamoto 862-8505, Japan

E-mail: nishimura.reiki@cityhosp-kumamoto.jp

Key words: breast cancer, recurrence, prognostic factor, Ki-67, survival after recurrence the Ki-67 index value in the primary tumor as an independent significant factor, particularly in luminal type tumors. The Ki-67 index value in the primary tumor was a significant prognostic factor for OS after disease recurrence. It is, therefore, important to take the Ki-67 index value into consideration for the treatment and follow-up of breast cancer patients.

\section{Introduction}

Breast cancer is a heterogeneous disease comprising different subtypes defined at the clinical, pathological and molecular levels. In clinical practice, the behavior of the various different types of breast cancer is variable. The assessment of hormone receptor and human epidermal growth factor receptor 2 (HER2) status at the time of breast cancer diagnosis is currently used as a guide to determine the appropriate adjuvant therapy. Estrogen receptor (ER) and HER2 expression are key factors for predicting the benefits of using endocrine and HER2-targeted therapies, respectively. Moreover, the Ki-67 index value is effective in discriminating between luminal A and B type tumors and the application of chemotherapy is commonly recommended for patients with a high Ki-67 value (1). The Ki-67 index value has attracted significant interest from clinical oncologists. Moreover, treatment decisions for recurrent cases are generally based on the ER and HER2 status in the primary tumor, disease-free interval (DFI), recurrence site and performance status (2).

The important biological markers in early breast cancer are tumor size, nuclear grade, proliferative activity (mitotic index and $\mathrm{Ki}-67$ index values), axillary lymph node involvement, ER, progesterone receptor $(\mathrm{PgR})$ and HER2 status. Uncontrolled proliferation is a key characteristic of malignant tumors and, therefore, tumor proliferation is one of the major factors associated with prognosis $(3,4)$. The mitotic index $(\mathrm{MI})$ and the $\mathrm{Ki}-67$ index value are the two most commonly used indices to measure proliferation. MI is defined as the number of mitoses at the periphery of the tumor (5) and is the main determinant of the histological grade (Nottingham system) (5). There is currently no standardization of the Ki-67 measurement and it has not yet been accepted as a routine biomarker (6). An international working group reported (7) that substantial variability in the $\mathrm{Ki}-67$ scoring procedure is observed among some of the world's most experienced laboratories and $\mathrm{Ki}-67$ values and cut-offs for clinical decision-making cannot be transferred 
between laboratories without first standardizing the scoring methodology. In our institute, the Ki-67 index value has been evaluated using immunohistochemistry (IHC) since 1987 in over 4,000 consecutive cases (8).

The use of the Ki-67 index value as a prognostic and predictive marker has been extensively investigated in the neoadjuvant as well as the adjuvant settings $(9,10)$. Certain studies reported that the $\mathrm{Ki}-67$ index value is a significant prognostic factor in terms of disease-free and overall survival after initial treatment $(8,11)$. However, other studies have questioned the usefulness of the Ki-67 index value as a prognostic factor after recurrence. Delpech et al (12) reported that high Ki-67 expression in the primary tumor remained an independent, adverse prognostic factor in metastatic disease. The Ki-67 index value in the primary tumor is important for deciding the treatment for recurrent cases. Therefore, it is important to elucidate the role and clinical significance of the Ki-67 index value in the primary tumor in recurrent breast cancer.

In this study, the Ki-67 index value was investigated in the primary breast cancer tumors and the association between the Ki-67 index value and the recurrence profile was also assessed. Moreover, the clinical significance of the $\mathrm{Ki}-67$ index value in the primary tumor was evaluated as a prognostic factor in recurrent breast cancer.

\section{Patients and methods}

Patients. Immunohistochemical analysis of the Ki-67 index was performed in 4,701 patients with primary breast cancer from 1987 until March, 2013 at Kumamoto City Hospital. Among these patients, there were 666 consecutive cases with recurrence after primary surgery. In terms of the patient characteristics (Table I), the mean age of the patients was 51.6 years (range, 25-95 years) and the mean tumor diameter was $3.1 \mathrm{~cm}$ (range, 0.5-17.0 cm). One-third $(33.3 \%$ ) of the patients had pathologically negative lymph nodes. The ER, PgR and HER 2 positive rates were 59.0, 40.7 and $18.8 \%$, respectively. The median value for DFI was 30.0 months and the DFI for 290 patients $(43.6 \%)$ was within 2 years. The predominant sites of recurrence were as follows; soft tissue, 260 cases $(39.1 \%)$; bone, 158 cases (23.7\%); and viscera, 248 cases (37.2\%).

Histopathological examination. The investigated factors included the presence or absence of lymph node metastasis, nuclear grade, ER/PgR status, proliferation (Ki-67 index) and HER2 overexpression in the primary tumor. The IHC for ER, PgR, Ki-67 and HER2 was performed as previously described (13). The positive cell rates for ER/PgR were determined by IHC and a value of $\geq 1 \%$ was considered as positive. The proliferative activity was determined by IHC for the Ki-67 antibody (Dako, Glostrup, Denmark). The fraction of proliferating cells (Ki-67-positive) was based on a count of at least 500 tumor cells in the peripheral area including the hot spot and the Ki-67 values were divided into 3 groups as previously reported (8), namely $<20, \geq 20$ and $\geq 50 \%$. HER 2 expression was evaluated by immunostaining (LSAB method) with the HercepTest (Dako). The staining pattern of HER2 was divided into four groups as follows: $3+$, strong and diffuse staining; $2+$, moderate and diffuse staining; $1+$, focal staining in $>10 \%$ of the cancer cells; and negative. All the IHC data, including the Ki-67 index value,
Table I. Patient characteristics $(n=666)$.

\begin{tabular}{|c|c|c|}
\hline Variables & Total & $\%$ \\
\hline \multicolumn{3}{|l|}{ Primary tumor } \\
\hline \multicolumn{3}{|l|}{ Menopausal status } \\
\hline Premenopausal & 353 & 53.0 \\
\hline Postmenopausal & 313 & 47.0 \\
\hline \multicolumn{3}{|l|}{ Nodal status } \\
\hline NO & 220 & 33.0 \\
\hline $\mathrm{N}+$ & 426 & 64.0 \\
\hline Unknown & 20 & 3.0 \\
\hline \multicolumn{3}{|l|}{ Nuclear grade } \\
\hline 1 & 119 & 17.9 \\
\hline 2 & 330 & 49.5 \\
\hline 3 & 107 & 16.1 \\
\hline Unknown & 110 & 16.5 \\
\hline \multicolumn{3}{|l|}{ ER status } \\
\hline$(+)$ & 393 & 59.0 \\
\hline$(-)$ & 273 & 41.0 \\
\hline \multicolumn{3}{|l|}{ PgR status } \\
\hline$(+)$ & 271 & 40.7 \\
\hline$(-)$ & 338 & 50.8 \\
\hline Unknown & 57 & 8.5 \\
\hline \multicolumn{3}{|l|}{ HER2 status } \\
\hline$(-)$ & 309 & 46.4 \\
\hline$(+)$ & 125 & 18.8 \\
\hline Unknown & 232 & 34.8 \\
\hline \multicolumn{3}{|l|}{ Subtype } \\
\hline Luminal & 221 & 33.2 \\
\hline Luminal/HER2 & 55 & 8.3 \\
\hline HER2-enriched & 70 & 10.5 \\
\hline Triple-negative & 88 & 13.2 \\
\hline Unknown & 232 & 34.8 \\
\hline
\end{tabular}

Recurrence

DFI (years)

$<2 \quad 290$

43.6

$<5 \quad 224$

33.6

$\geq 5 \quad 152$

22.8

Recurrence site

$\begin{array}{lll}\text { Soft tissue } & 260 & 39.1\end{array}$

Bone $\quad 158 \quad 23.7$

Viscera 248

37.2

Primary surgery
Age (years)
Mean \pm SD
$51.6 \pm 12.9$
Tumor size $(\mathrm{mm})$
Mean \pm SD $\quad 30.7 \pm 24.1$

ER, estrogen receptor; PgR, progesterone receptor; HER2, human epidermal growth factor receptor 2; DFI, disease-free interval. 
Table II. Clinicopathological factors and Ki-67 index in recurrent breast cancer.

\begin{tabular}{|c|c|c|c|c|c|c|c|}
\hline \multirow[b]{2}{*}{ Variables } & \multicolumn{3}{|c|}{ Ki-67 index, no. (\%) } & \multirow[b]{2}{*}{ Total } & \multirow[b]{2}{*}{ P-value } & \multicolumn{2}{|c|}{$\mathrm{Ki}-67$ index } \\
\hline & $<20 \%$ & $<50 \%$ & $\geq 50 \%$ & & & Median (\%) & P-value \\
\hline Menopausal status & & & & & 0.10 & & 0.08 \\
\hline Premenopausal & $102(28.9)$ & 157 & 94 & 353 & & 27.0 & \\
\hline Postmenopausal & $105(31.1)$ & 146 & 62 & 313 & & 26.0 & \\
\hline Nodal status & & & & & 0.41 & & 0.42 \\
\hline No & $75(34.1)$ & 101 & 44 & 220 & & 25.0 & \\
\hline $\mathrm{N}+$ & $131(30.8)$ & 191 & 104 & 426 & & 28.0 & \\
\hline Unknown & 1 & 11 & 8 & 20 & & & \\
\hline Nuclear grade & & & & & $<0.0001$ & & $<0.0001$ \\
\hline 1 & $57(47.9)$ & 50 & 12 & 119 & & 21.0 & \\
\hline 2 & $91(27.5)$ & 164 & 75 & 330 & & 29.5 & \\
\hline 3 & $13(12.1)$ & 50 & 44 & 107 & & 45.0 & \\
\hline Unknown & 46 & 39 & 25 & 110 & & & \\
\hline ER status & & & & & $<0.0001$ & & $<0.0001$ \\
\hline$(+)$ & $160(40.7)$ & 180 & 53 & 393 & & 24.0 & \\
\hline$(-)$ & 47 (17.2) & 123 & 103 & 273 & & 40.0 & \\
\hline PgR status & & & & & $<0.0001$ & & $<0.0001$ \\
\hline$(+)$ & $114(41.9)$ & 128 & 30 & 272 & & 30.0 & \\
\hline$(-)$ & $70(20.2)$ & 155 & 113 & 338 & & 43.0 & \\
\hline Unknown & 23 & 20 & 13 & 56 & & & \\
\hline HER2 status & & & & & $<0.0001$ & & $<0.0001$ \\
\hline$(-)$ & $96(31.1)$ & 139 & 74 & 309 & & 30.0 & \\
\hline$(+)$ & $16(12.8)$ & 88 & 21 & 125 & & 35.0 & \\
\hline Unknown & 95 & 76 & 61 & 232 & & & \\
\hline DFI (years) & & & & & $<0.0001$ & & $<0.0001$ \\
\hline$<2$ & $50(17.2)$ & 132 & 108 & 290 & & 40.5 & \\
\hline$<5$ & $81(36.2)$ & 106 & 37 & 224 & & 25.0 & \\
\hline$\geq 5$ & $76(50.0)$ & 65 & 11 & 152 & & 19.5 & \\
\hline Recurrence site & & & & & $<0.0001$ & & $<0.0001$ \\
\hline Soft tissue & $88(33.8)$ & 110 & 62 & 260 & & 26.5 & \\
\hline Bone & $60(38.0)$ & 75 & 23 & 158 & & 24.0 & \\
\hline Viscera & $59(23.8)$ & 118 & 71 & 248 & & 30.5 & \\
\hline Lung & $39(29.8)$ & 63 & 29 & 131 & & 27.0 & $<0.0001$ \\
\hline Liver & $16(19.8)$ & 41 & 24 & 81 & & 38.0 & \\
\hline Brain & $2(8.0)$ & 8 & 15 & 25 & & 55.0 & \\
\hline
\end{tabular}

ER, estrogen receptor; PgR, progesterone receptor; HER2, human epidermal growth factor receptor 2; DFI, disease-free interval.

were evaluated by two pathologists who were blinded to the patient data. ER-positive and HER2-negative tumors were classified as luminal type; ER-positive and HER2-positive tumors (HER2 IHC: $3+$ or $2+$ and FISH amplification ratio $>2.0$ ) as luminal/HER2 type; ER-negative and HER2-positive tumors as HER2-enriched disease; and ER-negative, PgR-negative and HER2-negative tumors as triple-negative (TN) type.

Treatment. Postoperative adjuvant therapy is being performed since 1999, based on the recommendations of the St. Gallen International Meeting (14). The chemotherapy regimen for the patients prior to 1999 was oral fluorouracil agents, a combination of cyclophosphamide + methotrexate + fluorouracil and anthracycline; from 1999 onwards, anthracycline and taxanes have been used. Trastuzumab was added as an adjuvant treatment in 2008; however, it has been used for patients with recurrence since 2001.

The systemic treatment for recurrent cases was determined based on ER and HER2 status in the primary tumor, DFI, recurrence site and performance status (2). In certain cases with recurrent breast cancer, local treatment, such as resection of the lesion and radiotherapy, was performed after obtaining informed consent from the patients. 

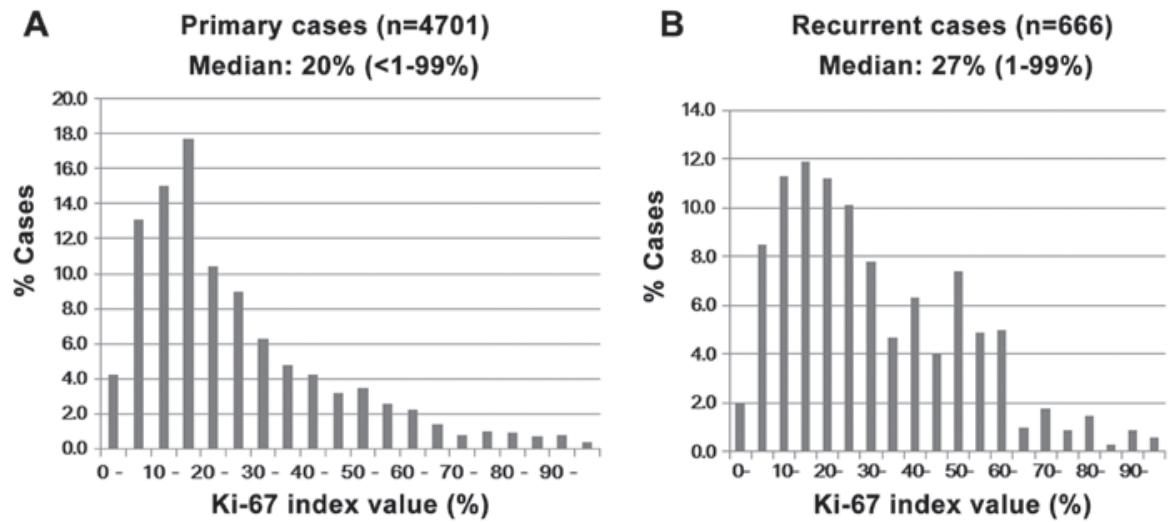

Figure 1. Distribution of Ki-67 index values in the primary breast cancer in all (A) primary and (B) recurrent cases. Several patients had a Ki-67 index of $10-19 \%$ in all the primary cases, with a median value of $20 \%$. However, recurrent cases did not display a clear peak and the number of high-value cases was increased. The median Ki-67 value was $27 \%$ in the recurrent cases.

A

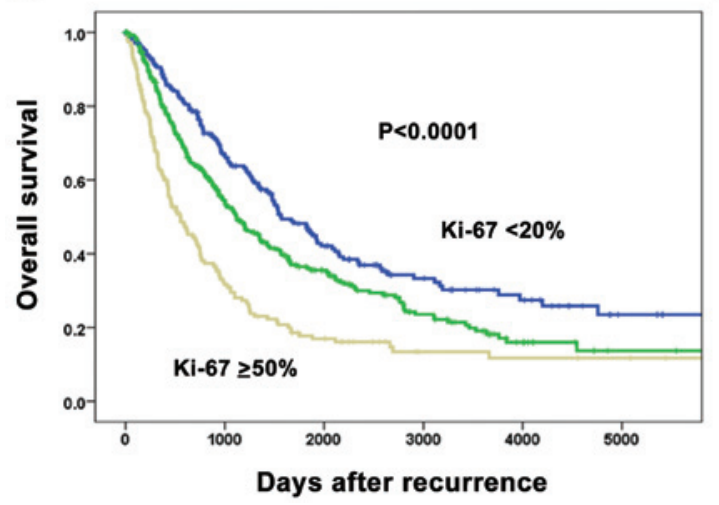

B

\begin{tabular}{ccc}
\hline Ki-67 & 5y OS (\%) & 10y OS (\%) \\
\hline$<20 \%$ & 47.5 & 28.8 \\
$<50 \%$ & 36.5 & 18.2 \\
$\geq 50 \%$ & 17.8 & 13.4 \\
\hline
\end{tabular}

Figure 2. Overall survival (OS) after breast cancer recurrence according to the Ki-67 index. (A) Patients with a higher Ki-67 index exhibited significantly lower OS rates after recurrence compared to those with a lower index. (B) The 5-year/10-year OS rates after recurrence were 47.5/28.8\%, 36.5/18.2\% and 17.8/13.4\% in each Ki-67 index group, respectively.

Statistical analysis. The statistical analysis included the Chi-square test and Fisher's exact test to perform inter-group comparisons (Table II). The Wilcoxon's (non-parametric) test was used to compare the mean or median values for tumor size, age and Ki-67 index value. The prognosis [overall survival (OS)] was calculated with the Kaplan-Meier method and tested with the log-rank procedure. The OS after recurrence was defined as the time from the diagnosis of recurrence to death from any cause. The Cox's proportional hazard model was used to perform univariate and multivariate analyses of the factors associated with $\mathrm{OS}$ after recurrence. A multivariate analysis was performed of only the cases without missing values. The median follow-up period was 65.9 months in the surviving group. The model was evaluated using the Harrell C-index (0-1.0) to determine whether the sample size was appropriate for analysis. A higher index value indicates that the sample size of the model is appropriate for analysis $(15,16)$. The sample size for this study had a C-index value of 0.68 , which means that the sample size was adequate.

\section{Results}

Distribution of Ki-67 index values in primary breast cancer and recurrent cases. A number of patients had a Ki-67 index value of $10-19 \%$ in all the primary cases and the median value was $20 \%$ (Fig. 1A). However, recurrent cases did not display a clear peak and the number of high-value cases increased. The median Ki-67 value was $27 \%$ in the recurrent cases (Fig. 1B).

Clinicopathological factors and $\mathrm{Ki}-67$ index in recurrent breast cancer. The Ki-67 index values were investigated in relation to clinicopathological factors (Table II). Nuclear grade, ER, PgR, HER2, DFI and recurrence site were significantly correlated with the Ki-67 index values. Patients with higher grade, ER-/PgR-negative, HER2-negative, with a shorter DFI and visceral metastasis had significantly higher $\mathrm{Ki}-67$ values. The median Ki-67 index value for nuclear grade, ER/PgR, HER2, DFI and metastatic site exhibited a similar statistical tendency as that seen in the categorical analysis. The Ki-67 index values for the recurrent sites were low (24\%) in patients with bone metastasis and higher in patients with liver or brain metastasis (38 and 55\%, respectively). The DFI was inversely correlated with the Ki-67 index values.

Overall survival after recurrence according to $\mathrm{Ki}-67$ index values. The association between Ki-67 index values and prognosis was investigated (Fig. 2). Patients with a higher Ki-67 index value had significantly lower OS rates after recurrence 
Table III. Uni- and multivariate analysis of factors for overall survival after recurrence.

\begin{tabular}{|c|c|c|c|c|c|}
\hline \multirow[b]{2}{*}{ Factor } & \multicolumn{3}{|c|}{ Univariate analysis } & \multicolumn{2}{|c|}{ Multivariate analysis } \\
\hline & \multicolumn{2}{|c|}{ HR (95\% CI) } & P-value & HR & P-value \\
\hline \multicolumn{6}{|l|}{ Menopausal status } \\
\hline Premenopausal & & 1.00 & 0.057 & 1.00 & 0.29 \\
\hline Postmenopausal & 0.84 & $(0.69-1.005)$ & & 0.88 & \\
\hline \multicolumn{6}{|l|}{ Tumor size $(\mathrm{cm})$} \\
\hline$<2.0$ & 0.64 & $(0.53-0.78)$ & $<0.0001$ & 1.06 & 0.69 \\
\hline$\geq 2.0$ & & 1.00 & & 1.00 & \\
\hline \multicolumn{6}{|l|}{ Nodal status } \\
\hline$(-)$ & 0.53 & $(0.43-0.65)$ & $<0.0001$ & 0.61 & 0.001 \\
\hline$(+)$ & & 1.00 & & 1.00 & \\
\hline \multicolumn{6}{|l|}{ Nuclear grade } \\
\hline 1 & 0.56 & $(0.40-0.78)$ & 0.001 & 0.92 & 0.68 \\
\hline 2 & 0.73 & $(0.56-0.93)$ & 0.013 & 1.14 & 0.39 \\
\hline 3 & & 1.00 & & 1.00 & \\
\hline \multicolumn{6}{|l|}{ Ki-67 index } \\
\hline$<20 \%$ & 0.44 & $(0.34-0.56)$ & $<0.0001$ & 0.65 & 0.01 \\
\hline$<50 \%$ & 0.60 & $(0.48-0.75)$ & $<0.0001$ & 0.70 & 0.009 \\
\hline$\geq 50 \%$ & & 1.00 & & 1.00 & \\
\hline \multicolumn{6}{|l|}{ ER status } \\
\hline$(-)$ & 1.79 & $(1.49-2.16)$ & $<0.0001$ & 1.20 & 0.23 \\
\hline$(+)$ & & 1.00 & & 1.00 & \\
\hline \multicolumn{6}{|l|}{ PgR status } \\
\hline$(-)$ & 1.88 & $(1.54-2.30)$ & $<0.0001$ & 1.26 & 0.12 \\
\hline$(+)$ & & 1.00 & & 1.00 & \\
\hline \multicolumn{6}{|l|}{ HER2 status } \\
\hline$(-)$ & 1.24 & $(0.95-1.62)$ & 0.12 & & \\
\hline$(+)$ & & 1.00 & & & \\
\hline \multicolumn{6}{|l|}{ DFI (years) } \\
\hline$<2$ & & 1.00 & & 1.00 & \\
\hline$<5$ & 1.54 & $(1.16-2.06)$ & $<0.0001$ & 1.27 & 0.21 \\
\hline$\geq 5$ & 2.86 & $(2.19-3.74)$ & 0.003 & 2.15 & $<0.0001$ \\
\hline \multicolumn{6}{|l|}{ Recurrence site } \\
\hline Soft tissue & 0.57 & $(0.46-0.71)$ & $<0.0001$ & 0.56 & $<0.0001$ \\
\hline Bone & 0.77 & $(0.61-0.97)$ & 0.028 & 0.94 & 0.67 \\
\hline Viscera & & 1.00 & & 1.00 & \\
\hline
\end{tabular}

HR, hormone receptor; ER, estrogen receptor; PgR, progesterone receptor; HER2, human epidermal growth factor receptor 2; DFI, disease-free interval.

compared to those with a lower index value (Fig. 2A). The 5-/10-year OS rates after recurrence were 47.5/28.8\%, $36.5 / 18.2 \%$ and $17.8 / 13.4 \%$ in each of the Ki-67 index groups, respectively (Fig. 2B).

Uni- and multivariate analysis of factors for overall survival after recurrence. Univariate and multivariate analyses were performed to identify the prognostic factors for OS after recurrence (Table III). The significant factors included tumor size, lymph node status, hormone dependency, Ki-67 index values, DFI and recurrence sites in the univariate analysis. The multivariate analysis revealed that lymph node status, Ki-67 index values, DFI and recurrence sites were significant factors for OS. Moreover, a multivariate analysis was performed in order to determine the prognostic factors according to each subtype. The analysis revealed that the Ki-67 index value was an independent factor only in the luminal type. An unexpected result of this analysis revealed that there were a number of other factors present in each of the subtypes (Table IV). 
Table IV. Multivariate analysis of factors for overall survival after disease recurrence according to breast cancer subtypes.

\begin{tabular}{llcccc}
\hline Factors & \multicolumn{1}{c}{ Category } & $\begin{array}{c}\text { Luminal } \\
\text { P-value }\end{array}$ & $\begin{array}{c}\text { Luminal/HER2 } \\
\text { P-value }\end{array}$ & $\begin{array}{c}\text { HER2 } \\
\text { P-value }\end{array}$ & $\begin{array}{c}\text { Triple-negative } \\
\text { P-value }\end{array}$ \\
\hline Menopausal status & Pre-/postmenopausal & 0.046 & 0.10 & 0.35 & 0.70 \\
Tumor size $(\mathrm{cm})$ & $<2.0 / \geq 2.0$ & 0.52 & 0.17 & 0.007 & 0.21 \\
Nodal status & $(-) /(+)$ & 0.37 & 0.98 & 0.034 & 0.93 \\
Nuclear grade & $1 / 2 / 3$ & 0.30 & 0.19 & 0.64 & 0.91 \\
Ki-67 value $(\%)$ & $<20 /<50 / \geq 50$ & 0.037 & 0.69 & 0.36 & 0.73 \\
DFI (years) & $<2 /<5 / \geq 5$ & $<0.0001$ & 0.36 & 0.11 & 0.067 \\
Recurrence site & Soft tissue/bone/viscera & 0.004 & 0.57 & 0.08 & 0.008 \\
\hline
\end{tabular}

HER2, human epidermal growth factor receptor 2; DFI, disease-free interval.

\section{Discussion}

This study included 4,701 cases of primary breast cancer, with 666 recurrent breast cancer patients at a single institution and the clinical significance of the Ki-67 index value as a prognostic marker after recurrence was evaluated. Moreover, the association between the Ki-67 index value and the clinicopathological factors that reflect prognosis was investigated.

There are several limitations that affect the standardization of the Ki-67 index biomarker. First, there is a difference in opinion among researchers with regards to which part of the field to assess. In this study, the hot spot (relatively dense concentration of cancer nuclei) was the main area evaluated. An overall average score was recommended by the International Ki67 in Breast Cancer Working Group (17). According to several studies $(18,19)$, the Ki-67 index value at the hot spot was significantly correlated with survival. The selection of hot spots is considered indispensable for the $\mathrm{Ki}-67$ index value assessment of breast cancer patients in a clinical setting. Second, there is a wide range of various $\mathrm{Ki}-67$ cut-off points among studies and researchers. The difficulty in defining a cut-off point does not mean that the Ki-67 biomarker is not effective for prognosis. The variability of the Ki-67 cut-off point is dependent on the clinical end points, the type of therapy, the distribution of cases and the molecular subtypes. In our institute, we adopted the cut-off points $20 \%$ and $50 \%$, as previous studies revealed that they were instrumental as reliable points. Moreover, the median value was $20 \%$ in all the primary cases and $50 \%$ in the cases with the TN type $(8,20,21)$.

The Ki-67 index values ranged from 1 to $99 \%$. The Ki-67 index value for the majority of the primary breast cancer tumors was $10-19 \%$ and the median value was $20 \%$. In the recurrent cases, there was no peak in the $\mathrm{Ki}-67$ index value and the median value was $27 \%$ in the primary tumor. These findings indicate that highly proliferative tumors tend to recur. Previous studies $(8,9)$ reported that the Ki-67 index value in the primary tumor was a prognostic factor for DFS and OS after initial treatment. However, the number of studies on the prognostic significance of the Ki-67 index value in recurrent breast cancer is currently limited. Delpech et al (12) reported that low Ki-67 expression in the primary tumor is associated with higher clinical benefit and longer time-to-progression on first-line endocrine therapy and longer survival after metastatic recurrence. In this study, we investigated whether the baseline $\mathrm{Ki}-67$ index value in the primary tumor is a useful prognostic factor after recurrence.

The findings also demonstrated that a higher Ki-67 index value was significantly correlated with a higher grade of malignancy for clinicopathological factors such as negative ER/PgR, higher grade and positive HER2. Moreover, patients with a higher Ki-67 index value exhibited a significantly shorter DFI and visceral metastasis, particularly liver and brain metastasis. Pathmanathan et al (22) reported a statistically significant difference in breast cancer-specific survival in the groups using Ki-67 and receptor status, whereas histological grading was not a significant predictor of survival in systemically untreated patients with node-negative breast cancer. The Ki-67 index value provides useful prognostic information beyond the traditionally assessed clinicopathological variables. It was reported that the Ki-67 index value was an independent prognostic factor in early breast cancer, particularly luminal type tumors $(8,23)$. A multivariate analysis by Reyal et al (18) revealed that the $\mathrm{Ki}-67$ index value remained the only significant prognostic factor in the subgroups of ER-positive and HER2-negative tumors. In addition, a multivariate analysis by Nishimura et al (20) revealed that the Ki-67 index value increased significantly from a mean of $29.1 \%$ in the primary tumor to $36.3 \%$ at relapse, indicating that the $\mathrm{Ki}-67$ level in the primary tumor is a significant factor for OS after recurrence. Ibrahim et al (24) reported that patients with a Ki-67 index value of $<20 \%$ exhibited a significantly higher post-recurrence survival compared to patients with a Ki-67 index value of $\geq 20 \%$. Moreover, the bone, lung/pleura and chest wall were common sites of recurrence in the early recurrence group with highly proliferative tumors and liver metastasis was identified in $13.6 \%$ of the patients (21). In the late recurrence group exhibiting low proliferation, recurrence was more common in the lung/pleura and bone; however, liver and brain metastases were rarely encountered.

In the present study, the Ki-67 index value in the primary tumor was an independent significant prognostic factor in ER-positive and HER2-negative tumors in recurrent breast cancer. The Ki-67 index value was found to be correlated with DFI and recurrence site. Furthermore, the values were 
low $(24 \%)$ in patients with bone metastasis, whereas patients with liver or brain metastasis exhibited higher values (38 and $55 \%$, respectively). These findings suggest that the Ki-67 index value is correlated with survival after breast cancer recurrence as well as the recurrence sites.

In conclusion, we demonstrated that the baseline Ki-67 index value in the primary tumor was a useful prognostic factor after breast cancer recurrence. The median Ki-67 index value at baseline was $20 \%$ in all the primary cases and $27 \%$ in the recurrent cases. The $\mathrm{Ki}-67$ index values for the recurrent sites were low (24\%) in patients with bone metastasis and higher in patients with liver or brain metastasis (38 and 55\%, respectively). The DFI was found to be inversely correlated with the Ki-67 index values. Moreover, a multivariate analysis for OS after recurrence revealed that the $\mathrm{Ki}-67$ index value in the primary tumor was an independent significant factor only in luminal type tumors. The Ki-67 index value provides important data associated with recurrence time and recurrence site that are crucial for designing a suitable treatment plan for patients and for an accurate prediction of prognosis. Therefore, the Ki-67 index value should be taken into consideration in the treatment and follow-up of breast cancer patients.

\section{Acknowledgements}

We would like to express our gratitude to the staff of the Department of Pathology at Kumamoto City Hospital for their technical assistance and for the collection of cancer tissue samples.

\section{References}

1. Goldhirsch A, Ingle JN, Gelber RD, Coates AS, Thürlimann B and Senn HJ; Panel members: Thresholds for therapies: highlights of the St Gallen International Expert Consensus on the primary therapy of early breast cancer 2009. Ann Oncol 20: 1319-1329, 2009.

2. Hortobagyi GN: Treatment of breast cancer. N Engl J Med 339: 974-984, 1998

3. Colozza M, Azambuja E, Cardoso F, Sotiriou C, Larsimont D and Piccart MJ: Proliferative markers as prognostic and predictive tools in early breast cancer: where are we now? Ann Oncol 16 : $1723-1739,2005$.

4. Stuart-Harris R, Caldas C, Pinder SE and Pharoah P: Proliferation markers and survival in early breast cancer: a systematic review and meta-analysis of 85 studies in 32,825 patients. Breast 17: 323-334, 2008

5. Elston CW and Ellis IO: Pathological prognostic factors in breast cancer. I. The value of histological grade in breast cancer: experience from a large study with long-term follow-up. Histopathology 19: 403-410, 1991.

6. Harris L, Fritsche H, Mennel R, et al: American Society of Clinical Oncology 2007 update of recommendations for the use of tumor markers in breast cancer. J Clin Oncol 25: 5287-5312, 2007.

7. Polley MY, Leung SC, McShane LM, Gao D, Hugh JC, Mastropasqua MG, Viale G, Zabaglo LA, Penault-Llorca F, Bartlett JM, Gown AM, Symmans WF, Piper T, Mehl E, Enos RA, Hayes DF, Dowsett M and Nielsen TO; International Ki67 in Breast Cancer Working Group of the Breast International Group and North American Breast Cancer Group: An international Ki67 reproducibility study. J Natl Cancer Inst 105: 1897-1906, 2013.
8. Nishimura R, Osako T, Okumura Y, Hayashi M, Toyozumi Y and Arima N: Ki-67 as a prognostic marker according to breast cancer subtype and a predictor of recurrence time in primary breast cancer. Exp Ther Med 1: 747-754, 2010.

9. de Azambuja E, Cardoso F, de Castro G Jr, et al: Ki-67 as prognostic marker in early breast cancer: a meta-analysis of published studies involving 12155 patients. Br J Cancer 96: 1504-1513, 2007.

10. Jonat $\mathrm{W}$ and Arnold $\mathrm{N}$ : Is the $\mathrm{Ki}-67$ labelling index ready for clinical use? Ann Oncol 22: 500-502, 2011.

11. Yerushalmi R, Woods R, Ravdin PM, Hayes MM and Gelmon KA: Ki67 in breast cancer: prognostic and predictive potential. Lancet Oncol 11: 174-183, 2010.

12. Delpech Y, Wu Y, Hess KR, Hsu L, Ayers M, Natowicz R, Coutant C, Rouzier R, Barranger E, Hortobagyi GN, Mauro D and Pusztai L: Ki67 expression in the primary tumor predicts for clinical benefit and time to progression on first-line endocrine therapy in estrogen receptor-positive metastatic breast cancer. Breast Cancer Res Treat 135: 619-627, 2012.

13. Kai K, Nishimura R, Arima N, Miyayama H and Iwase H: p53 expression status is a significant molecular marker in predicting the time to endocrine therapy failure in recurrent breast cancer: a cohort study. Int J Clin Oncol 11: 426-433, 2006.

14. Goldhirsch A, Glick JH, Gelber RD and Senn HJ: Meeting highlights: International Consensus Panel on the Treatment of Primary Breast Cancer. J Natl Cancer Inst 90: 1601-1608, 1998.

15. Taktak AF, Eleuteri A, Lake SP and Fisher AC: A web-based tool for the assessment of discrimination and calibration properties of prognostic models. Comput Biol Med 38: 785-791, 2008.

16. Harrell FE Jr, Califf RM, Pryor DB, et al: Evaluating the yield of medical tests. JAMA 247: 2543-2546, 1982.

17. Dowsett M,Nielsen TO, A'Hern R, Bartlett J, Coombes RC, Cuzick J, Ellis M, Henry NL, Hugh JC, Lively T, McShane L, Paik S, Penault-Llorca F, Prudkin L, Regan M, Salter J, Sotiriou C, Smith IE, Viale G, Zujewski JA and Hayes DF; International Ki-67 in Breast Cancer Working Group: Assessment of Ki67 in breast cancer: recommendations from the International Ki67 in Breast Cancer Working Group. J Natl Cancer Inst 103: 1656-1664, 2011.

18. Reyal F, Hajage D, Savignoni A, et al: Long-term prognostic performance of Ki67 rate in early stage, pT1-pT2, pN0, invasive breast carcinoma. PLoS One 8: e55901, 2013.

19. Honma N, Horii R, Iwase T, Saji S, Younes M, Ito Y and Akiyama F: Ki-67 evaluation at the hottest spot predicts clinical outcome of patients with hormone receptor-positive/ HER2-negative breast cancer treated with adjuvant tamoxifen monotherapy. Breast Cancer: Mar 12, 2013 (Epub ahead of print).

20. Nishimura R, Osako T, Okumura Y, Tashima R, Toyozumi Y and Arima N: Changes in the ER, PgR, HER2, p53 and Ki-67 biological markers between primary and recurrent breast cancer: discordance rates and prognosis. World J Surg Oncol 9: 131-137, 2011.

21. Nishimura R, Osako T, Nishiyama Y, Tashima R, Nakano M, Fujisue M, Toyozumi $\mathrm{Y}$ and Arima N: Evaluation of factors related to late recurrence - later than 10 years after the initial treatment - in primary breast cancer. Oncology 85: 100-110, 2013.

22. Pathmanathan N, Balleine RL, Jayasinghe UW, Bilinski KL, Provan PJ, Byth K, Bilous AM, Salisbury EL and Boyages J: The prognostic value of Ki67 in systemically untreated patients with node-negative breast cancer. J Clin Pathol 67: 222-228, 2014.

23. Ribelles N, Perez-Villa L, Jerez JM, Pajares B, Vicioso L, Jimenez B, de Luque V, Franco L, Gallego E, Marquez A, Alvarez M, Sanchez-Muñoz A, Perez-Rivas L and Alba E: Pattern of recurrence of early breast cancer is different according to intrinsic subtype and proliferation index. Breast Cancer Res 15: R98, 2013.

24. Ibrahim T, Farolfi A, Scarpi E, Mercatali L, Medri L, Ricci M, Nanni O, Serra L and Amadori D: Hormonal receptor, human epidermal growth factor receptor-2, and Ki67 discordance between primary breast cancer and paired metastases: clinical impact. Oncology 84: 150-157, 2013. 